\title{
Eicosanoids as Risk and Prognostic Factors for Acute Respiratory Distress Syndrome in Sepsis Patients
}

\author{
Gaku Takahashi*, Shigehiro Shibata and Shigeatsu Endo
}

Department of Critical Care Medicine, Iwate Medical University, Japan

\begin{abstract}
Although a number of studies have reported elevated levels of eicosanoids in acute lung injury with sepsis, the possibility that eicosanoids may act as risk and prognostic factors for sepsis patients who develop acute respiratory distress syndrome (ARDS) remains poorly studied. To clarify this aspect, we measured the levels of eicosanoids and used logistic regression analysis and receiver operating characteristic (ROC) curves to investigate whether eicosanoids could act as risk and prognostic factors for sepsis patients who develop ARDS. We conducted a casecontrol study comparing 13 sepsis patients with ARDS and 23 sepsis patients without ARDS. The plasma levels of leukotriene $B_{4}\left(L_{T B}\right)$, 6-keto-prostaglandin $F_{1 a}$ (6-keto-PGF $\left.{ }_{1 a}\right)$ and thromboxane $B_{2}\left(T X B_{2}\right)$ were measured by radioimmunoassays as substitutes for the plasma levels of $P \mathrm{PGI}_{2}$ and $T X A_{2}$, which are unstable. The levels of eicosanoids in sepsis patients with ARDS were significantly higher than those in sepsis patients without ARDS. Logistic regression analysis revealed that $\mathrm{LTB}_{4}$ was the only risk factor for sepsis patients with ARDS (odds ratio, $1.10 ; P=0.02)$. The area under the $R O C$ curve values for all eicosanoids were significantly greater than $0.5(P<0.001)$, and the likelihood value for the TXB ${ }_{2}$ levels was higher than those of the other eicosanoids. We conclude that LTB may be an important risk factor for sepsis patients with ARDS, while TXA may be an important prognostic factor for sepsis patients with ARDS.
\end{abstract}

Keywords: Leukotriene $\mathrm{B}_{4}$; Thromboxane $\mathrm{A}_{2}$; Prostaglandin $\mathrm{I}_{2}$; Lung injury; Logistic regression analysis; Receiver operating characteristic curve

\section{Introduction}

Acute respiratory distress syndrome (ARDS) is known to be associated with systemic inflammatory response syndrome (SIRS) through sepsis, and the inflammatory response is produced by inflammatory cells and/or endotoxins. Various inflammatory mediators lead to a critical event in the development of organ injury in the microvessels of organs, especially thelungs. Leukotrienes, thromboxanes and prostaglandins, collectively referred to as eicosanoids, have been reported to be involved in sepsis [1-4], burns [5] and ARDS [6,7]. Leukotrienes contribute to pulmonary edema by inducing neutrophil influx and activation and increasing vascular permeability. Leukotriene $\mathrm{B}_{4}\left(\mathrm{LTB}_{4}\right)$, which is derived by 5 -lipoxygenation of arachidonic acid, is synthesized by neutrophils, monocytes, macrophages and endothelial cells, and promotes neutrophil attachment to the vascular endothelium and lung injury [8]. Thromboxane $\mathrm{A}_{2}$ (TXA ${ }_{2}$ ) mediates the aggregation and release mechanism of platelets and is also a potent vasoconstrictor [9], while prostaglandin $\mathrm{I}_{2}\left(\mathrm{PGI}_{2}\right)$ is a potent endogenous inhibitor of platelet aggregation and a vasodilator [10]. Thus, eicosanoids are involved in the pathological process of lung injury. However, few studies have clinically and systematically investigated the pathophysiological changes in sepsis patients who develop ARDS. In the present study, we measured the plasma levels of the eicosanoids $\mathrm{LTB}_{4}, \mathrm{TXB}_{2}$ and 6-keto$\mathrm{PGF}_{1 \alpha}$ and used logistic regression analysis and receiver operating characteristic (ROC) curves to determine which eicosanoids act as risk and prognostic factors for sepsis patients who develop ARDS.

\section{Materials and Methods}

After obtaining informed consent from the patients or their families and approval to conduct the study from the Ethics Committee of our hospital, 36 adult sepsis patients were enrolled and assigned into 23 ARDS-free patients (14 males and 9 females; mean age, 57.78 years; age range, 51.08-64.48 years) and 13 ARDS patients (10 males and 3 females; mean age, 59.23 years; age range, 49.51-68.96 years). There were no significant differences between the groups regarding age or sex. The criteria for the diagnosis of ARDS were: $\mathrm{PaO}_{2} / \mathrm{FiO}_{2}(\mathrm{P} / \mathrm{F}$ ratio) $\leq 200 \mathrm{mmHg}$; absence of cardiac failure; pulmonary edema-like shadows on a chest X-ray; and pulmonary artery wedge pressure $\leq 18$ $\mathrm{mmHg}$ when measured [11]. The criterion for the diagnosis of sepsis was a systemic response to infection, manifested by two or more of the following conditions: body temperature $>38^{\circ} \mathrm{C}$ or $<36^{\circ} \mathrm{C}$; heart rate $>90$ beats/minute; respiratory rate $>20$ breaths/minute or $\mathrm{PaCO}_{2}<32$ $\mathrm{mmHg}$; and white blood cell count $>12,000 / \mathrm{mm}^{3}$ or $<4000 / \mathrm{mm}^{3}$, or $>10 \%$ immature (band) forms [12]. All the patients in the ARDS group had been endotracheally intubated and were on mechanical ventilation in the synchronized intermittent mandatory ventilation mode under intravenous sedation with midazolam 3-4 $\mathrm{mg} \cdot \mathrm{h}^{-1}$ and buprenorphine $0.03 \mathrm{mg} / \mathrm{h}$.

The methods for measuring the plasma eicosanoid levels were reported previously [5]. Briefly, blood samples were obtained from the ARDS patients within $24 \mathrm{~h}$ of ARDS onset and from the ARDSfree patients on the day of admission to the intensive care unit. All blood samples were collected into tubes containing indomethacinsupplemented $4.5 \mathrm{mM}$ ethylenediaminetetraacetic acid (EDTA) and centrifuged at $3000 \mathrm{rpm}$ for $15 \mathrm{~min}$ to obtain the plasma. For the $\mathrm{LTB}_{4}$ assay, the plasma was mixed with a mixture of ethyl acetate and methanol (2:1) and centrifuged at $3000 \mathrm{rpm}$ for $15 \mathrm{~min}$ to obtain the supernatant. All plasma samples were stored at $-80^{\circ} \mathrm{C}$ until analysis. $\mathrm{LTB}_{4}$, 6-keto-PGF $\mathrm{Pa}_{1 a}$ and $\mathrm{TXB}_{2}$ were measured by radioimmunoassays (MEN Research Products, DuPont, Boston, MA). The normal ranges

*Corresponding author: Gaku Takahashi, Department of Critical Care Medicine Iwate Medical University, 19-1 Uchimaru, Morioka, 020-8505, Japan, Tel: 81196515111; Fax: 811965105313; E-mail: gakut@iwate-med.ac.jp

Received December 04, 2017; Accepted December 07, 2017; Published December 14, 2017

Citation: Takahashi G, Shibata S, Endo S (2017) Eicosanoids as Risk and Prognostic Factors for Acute Respiratory Distress Syndrome in Sepsis Patients. J Pulm Respir Med 7: 435. doi: 10.4172/2161-105X.1000435

Copyright: (c) 2017 Takahashi G, et al. This is an open-access article distributed under the terms of the Creative Commons Attribution License, which permits unrestricted use, distribution, and reproduction in any medium, provided the original author and source are credited. 
for the levels of $\mathrm{LTB}_{4}$, 6-keto-PGF ${ }_{1 \alpha}$ and $\mathrm{TXB}_{2}$ were $77.0 \pm 15.7,12$ 33 and $14-50 \mathrm{pg} / \mathrm{ml}$, respectively. ROC curves for the eicosanoids were constructed for the sepsis patients with ARDS. We plotted the true-positive rate (sensitivity) on the vertical axis of the graph against the false-positive rate (1-specificity) on the horizontal axis for each threshold. An ideal test should have high sensitivity and low (1-specificity), and therefore produce a curve close to the upper left corner of the graph. The best cut-off points for eicosanoids as prognostic factors were identified as those values that simultaneously maximized the sensitivity and specificity. The likelihood ratios (LRs), defined as the ratio of the frequency of a finding among the diseased patients (truepositive rate) to the frequency of the finding among the non-diseased patients (false-positive rate), and the sensitivity/(1-specificity) ratios were also calculated. A true diagnostic test usually has an $L R>10$, while an exclusion test has an $\mathrm{LR}<0.1$. The data are reported as means and 95\% confidence intervals (CIs). Mann-Whitney tests were used for comparisons of the eicosanoid levels between ARDS and ARDS-free patients. All analysis were performed using the StatView J4.5 software (Abacus Concepts, Berkeley, CA). The ROC curves and logistic regressions were analyzed using SPSS (Chicago, IL). Values of $\mathrm{P}<0.05$ were considered statistically significant.

\section{Results}

Table 1 compares the eicosanoid levels in the ARDS and ARDSfree patients. The levels of all three factors were significantly higher in the ARDS patients than in the ARDS-free patients $\left(\mathrm{LTB}_{4}, \mathrm{P}<0.0001\right.$; $\mathrm{TXB}_{2}, \mathrm{P}<0.0001 ; 6$-keto- $\left.\mathrm{PGF}_{1 \mathrm{a}}, \mathrm{P}<0.001\right)$. Table 2 shows the logistic regression analysis for the eicosanoids in the ARDS patients. The values of the odds ratios for $\mathrm{LTB}_{4}, \mathrm{TXB}_{2}$ and 6-keto-PGF $\mathrm{F}_{1 \alpha}$ were 1.10 (95\% CI, 1.01-1.19; $\mathrm{P}=0.02$ ), 1.04 (95\% CI, 0.98-1.11; $\mathrm{P}=0.17$ ) and 0.99 (95\% CI, 0.83-1.19; $\mathrm{P}=0.95)$, respectively. Table 3 and Figure 1 show the ROC curves for the eicosanoids generated for the ARDS patients. The area under the ROC curve values for $\mathrm{LTB}_{4}, \mathrm{TXB}_{2}$ and 6-keto-PGF $\mathrm{P}_{1 \alpha}$ were 0.933 (95\% CI, 0.856-1.010; $\mathrm{P}<0.001$ ), 0.905 (95\% CI, 0.728-1.000; $\mathrm{P}<0.001$ ) and 0.878 (95\% CI, 0.485-0.990; $\mathrm{P}<0.001$ ), respectively. Table 4 shows the best cut-off points, sensitivities, specificities and LR values. The LR values for $\mathrm{LTB}_{4}, \mathrm{TXB}_{2}$ and 6-keto-PGF ${ }_{1 \alpha}$ were 7.95, 14.30 and 12.37 , respectively.

\begin{tabular}{|c|c|c|c|}
\hline Eicosanoids & ARDS (-) & ARDS (+) & $P$ value \\
\hline LTB4 (pg.ml-1) & $62.7(52.0-73.4)$ & $118.3(101.8-134.8)$ & $<0.0001$ \\
\hline TXB2 (pg.ml-1) & $38.1(26.5-49.7)$ & $94.2(71.0-117.3)$ & $<0.0001$ \\
\hline 6-keto-PGF ${ }_{10}\left(\right.$ pg.ml-1 $\left.{ }^{-1}\right)$ & $15.6(11.7-19.6)$ & $32.2(25.2-39.3)$ & 0.0002 \\
\hline
\end{tabular}

Table 1: Comparisons of eicosanoids in the ARDS and ARDS-free sepsis patients.

\begin{tabular}{|c|c|c|c|}
\hline Eicosanoids & Odds Ratio & 95\% Confidence Interval & P value \\
\hline LTB $_{4}$ & 1.10 & $1.01-1.19$ & 0.02 \\
\hline $\mathrm{TXB}_{2}$ & 1.04 & $0.98-1.11$ & 0.17 \\
\hline 6-keto-PGF & 0.99 & $0.83-1.19$ & 0.95 \\
\hline
\end{tabular}

Table 2: Logistic regression analysis of eicosanoids for ARDS in sepsis patients.

\begin{tabular}{|c|c|c|c|}
\hline Eicosanoids & AUC & 95\% Confidence Interval & P value* $^{*}$ \\
\hline LTB $_{4}$ & 0.933 & $0.856-1.010$ & $<0.001$ \\
\hline $\mathrm{TXB}_{2}$ & 0.905 & $0.728-1.000$ & $<0.001$ \\
\hline 6-keto-PGF & 0.878 & $0.485-0.990$ & $<0.001$ \\
\hline ROC: Receiver Operating Characteristic, AUC: Area Under the Curve,
\end{tabular}

${ }^{*}$ Comparison with $\mathrm{AUC}=0.5$

Table 3: ROC curve analysis of eicosanoids for ARDS in sepsis patients.

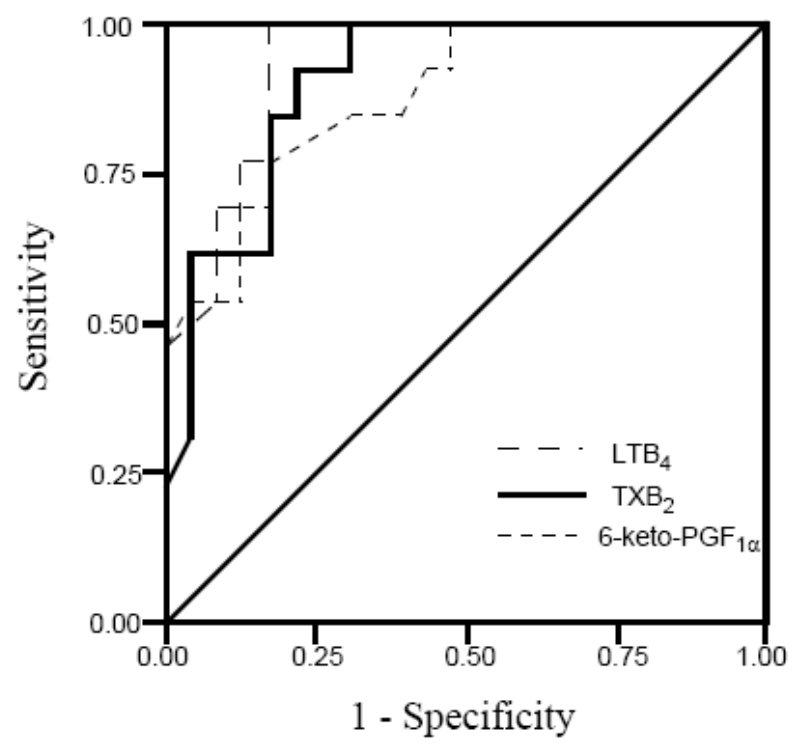

Figure 1: Receiver operating characteristic (ROC) curves for sepsis patients with ARDS. The area under the ROC curve (AUC) values for $\mathrm{LTB}_{4}, \mathrm{TXB}_{2}$ and 6-keto-PGF ${ }_{1 \alpha}$ are $0.933^{*}, 0.905^{*}$ and $0.878^{*}$, respectively. ${ }^{*} \mathrm{P}<0.001$ for $\mathrm{AUC}$ vs. $50 \%$.

\begin{tabular}{|c|c|c|c|c|}
\hline Eicosanoids & Cut-off Point & Sensitivity & Specificity & LR \\
\hline $\mathrm{LTB}_{4}\left(\right.$ pg.ml $\left.\mathrm{ml}^{-1}\right)$ & 103.5 & 0.69 & 0.91 & 7.95 \\
\hline $\mathrm{TXB}_{2}\left(\mathrm{pg} \cdot \mathrm{ml}^{-1}\right)$ & 83 & 0.62 & 0.96 & 14.3 \\
\hline 6-keto-PGF ${ }_{1 \mathrm{a}}\left(\mathrm{pg} \cdot \mathrm{ml}^{-1}\right)$ & 35 & 0.54 & 0.96 & 12.37 \\
\hline \multicolumn{5}{|l|}{ LR: Likelihood Ratio } \\
\hline
\end{tabular}

Table 4: Best cut-off points.

\section{Discussion}

We measured the plasma levels of three eicosanoids in sepsis patients, and determined whether any of these eicosanoids could act as risk and prognostic factors for sepsis patients who develop ARDS. Our study had four main findings: 1) the levels of all three eicosanoids were significantly higher in the ARDS patients than in the ARDS-free patients; 2) only $\mathrm{LTB}_{4}$ was a risk factor for sepsis patients with ARDS; 3) all three eicosanoids were specific factors for ARDS; and 4) the likelihood value of the $\mathrm{TXB}_{2}$ levels was higher than those of the other eicosanoids.

The present study provides information that will be useful for elucidating the process and mechanism of lung injury and for establishing therapeutic strategies in the future. Receptor antagonist and/or synthetase inhibitor analysis have been carried out in patients with ARDS. Thromboxane synthesis inhibitors and/or antagonists improved the acute cardiopulmonary effects of bolus endotoxin [13-15] and increased patient survival [16-18]. The thromboxane $A_{2}$ synthesis inhibitor ketoconazole was found to significantly reduce the rate of ARDS development in sepsis patients and decrease their mortality rate [19]. In contrast, ketoconazole was not found to reduce the mortality or duration of mechanical ventilation in a randomized trial [20]. The beneficial effects of ketoconazole may be attributed to the inhibition of leukotriene formation as well as thromboxane $A_{2}$ synthesis [7]. The results of the present study revealed that the likelihood value of the $\mathrm{TXB}_{2}$ levels was higher than those of the other eicosanoids examined, 
and that TXA $_{2}$ is a prognostic factor for sepsis patients with ARDS rather than a factor for treatments.

Amat et al. [7] analyzed the leukotrienes $\mathrm{LTB}_{4}, \mathrm{LTC}_{4}$ and $\mathrm{LTD}_{4}$, and reported that only the plasma concentration of $\mathrm{LTB}_{4}$ on day 1 was a prognostic marker for ARDS, and that $\mathrm{LTB}_{4}$ and interleukin- 8 together could be useful markers of the mortality rate. Leukotriene antagonists, such as ONO-1078 [21], LY255283 [22] and ICI 198,615 [23], seemed to ameliorate the clinical outcome in models of LPS-induced acute lung injury. These antagonists reduced pulmonary extravascular water contents and bronchoalveolar lavage fluid protein concentrations. Moreover, cytosolic phospholipase $\mathrm{A}_{2}\left(\mathrm{CPLA}_{2}\right)$ is important in the pathogenesis of sepsis-induced ARDS, and $\mathrm{LTB}_{4}$ is probably the major mediator of polymorphonuclear neutrophil infiltration among the $\mathrm{CPLA}_{2}$ products $[24,25]$. The results of the present study indicate that $\mathrm{LTB}_{4}$ is a factor for ARDS treatments in sepsis patients rather than a prognostic factor. However, few randomized trials of $\mathrm{LTB}_{4}$ antagonists have been carried out in sepsis patients with ARDS.

\section{Conclusion}

In conclusion, among the eicosanoids examined, $\mathrm{LTB}_{4}$ may be an important risk factor for sepsis patients who develop ARDS, while TXA may be an important prognostic factor for sepsis patients who develop ARDS. Molecular biological studies and large randomized trials are needed to confirm these findings.

\section{References}

1. Ball HA, Cook JA, Wise WC, Halushka PV (1986) Role of thromboxane, prostaglandins and leukotrienes in endotoxic and septic shock. Intensive Care Med 12: 116-126.

2. Takakuwa T, Endo S, Nakae H, Suzuki T, Inada K, et al. (1994) Relationships between plasma levels of type-II phospholipase A2, PAF-acetylhydrolase, leukotriene B4, complements, endothelin-1, and thrombomodulin in patients with sepsis. Res Commun Mol Pathol Pharmacol 84: 271-281.

3. Nakae H, Endo S, Inada K, Watanabe M, Baba N, et al. (1994) Relationship between leukotriene B4 and prostaglandin 12 in patients with sepsis. Res Commun Mol Pathol Pharmacol 86: 37-42

4. Nakae H, Endo S, Inada K, Yaegashi Y, Takakuwa T, et al. (1996) Nitrite/nitrate (NOX) and type II phospholipase A2, leukotriene B4, and platelet-activating factor levels in patients with septic shock. Res Commun Mol Pathol Pharmacol 92: 131-139.

5. Nakae H, Endo S, Inada K, Yamashita H, Yamada Y, et al. (1995) Plasma concentrations of type II phospholipase A2, cytokines and eicosanoids in patients with burns. Burns 21: 422-426.

6. Deby-Dupont G, Braun M, Lamy M, Deby C, Pincemail J, et al. (1987) Thromboxane and prostacyclin release in adult respiratory distress syndrome. Intensive Care Med 13: 167-174.

7. Amat M, Barcons M, Mancebo J, Mateo J, Oliver A, et al. (2000) Evolution of leukotriene B4, peptide leukotrienes, and interleukin-8 plasma concentrations in patients at risk of acute respiratory distress syndrome and with acute respiratory distress syndrome: mortality prognostic study. Crit Care Med 28: 57-62.

8. Ford-Hutchinson AW, Bray MA, Doig MV, Shiply ME, Smith MJH (1980)
Leukotriene B, a potent chemokinetic and aggregating substance released from polymorphonuclear leukocytes. Nature 286: 264-265.

9. Hamberg M, Svensson J, Samuelsson B (1975) Thromboxanes: A new group of biologically active compounds derived from prostaglandin endoperoxides. Proc Natl Acad Sci USA 72: 2994-2998.

10. Armstrong JM, Lattimer N, Moncada S, Vane JR (1978) Comparison of the vasodepressor effects of prostacyclin and 6-oxo-prostaglandin F1alpha with those of prostaglandin E2 in rats and rabbits. Br J Pharmacol 62: 125-130.

11. Bernard GR, Artigus A, Brigham KL, Carlet J, Falke K, et al. (1994) The American-European Consensus Conference on ARDS. Definitions, mechanisms, relevant outcomes, and clinical trial coordination. Am J Respir Crit Care Med 149: 818-824.

12. Bone RC, Balk RA, Cerra FB, Dellinger RP, Fein AM, et al. (1992) Definitions for sepsis and organ failure and guidelines for the use of innovative therapies in sepsis. Chest 101: 1644-1655.

13. Casey LC, Fletcher JR, Zmudka MI, Ramwell PW (1982) Prevention of endotoxin-induced pulmonary hypertension in primates by the use of a selective thromboxane synthetase inhibitor, OKY 1581. J Pharmacol Exp Ther 222: 441-446.

14. Watkins WD, Huttemeier PC, Kong D, Peterson MB (1982) Thromboxane and pulmonary hypertension following $E$. coli endotoxin infusion in sheep: Effect of an imidazole derivative. Prostaglandins 23: 273-285.

15. Armstrong RA, Jones RL, Wilson NH (1985) Effect of the thromboxane receptor antagonist EP 092 on endotoxin shock in the sheep. Prostaglandins 29: 703-713.

16. Cook JA, Wise WC, Halushka PV (1980) Elevated thromboxane levels in the rat during endotoxic shock: protective effects of imidazole, 13-azaprostanoic acid, or essential fatty acid deficiency. J Clin Invest 65: 227-230.

17. Wise WC, Cook JA, Halushka PV, Knapp DR (1980) Protective effects of thromboxane synthetase inhibitors in rats in endotoxic shock. Circ Res 46 : 854-859.

18. Anderegg K, Anzeveno P, Cook JA, Halushka PV, McCarthy J, et al. (1983) Effects of a pyridine derivative thromboxane synthetase inhibitor and its inactive isomer in endotoxic shock in the rat. Br J Pharmacol 78: 725-732.

19. Yu M, Tomasa G (1993) A double-blind, prospective, randomized trial of ketoconazole, a thromboxane synthetase inhibitor, in the prophylaxis of the adult respiratory distress syndrome. Crit Care Med 21: 1635-1642.

20. The ARDS Network (2000) Ketoconazole for early treatment of acute lung injury and acute respiratory distress syndrome: a randomized controlled trial. JAMA 283: 1995-2002.

21. Ishizaka A, Hasegawa N, Sakamaki F, Tasaka S, Nakamura H, et al. (1994) Effects of ONO-1078, a peptide leukotriene antagonist, on endotoxin-induced acute lung injury. Am J Respir Crit Care Med 150: 1325-1331.

22. Fink MP, O'Sullivan BP, Menconi MJ, Wollert PS, Wang H, et I. (1993) A novel leukotriene B4-receptor antagonist in endotoxin shock: A prospective, controlled trial in a porcine model. Crit Care Med 21: 1825-1837.

23. Schutzer KM, Larsson A, Risberg B, Falk A (1994) Leukotriene receptor antagonism prevents lung protein leakage and hypoxaemia in a septic cat model. Eur Respir J 7: 1131-1137.

24. Yokomizo T, Izumi T, Chang K, Takuma Y, Shimizu T (1997) A G-proteincoupled receptor for leukotriene B4 that mediates chemotaxis. Nature 387: 620-624.

25. Nagase N, Uozumi N, Aoki-Nagase T, Terawaki K, Ishii S, et al. (2003) A potent inhibitor of cytosolic phospholipase A2, arachidonyltrifluoromethyl ketone, attenuates LPS-induced ling injury in mice. Am J Physiol Lung Cell Mol Phisiol 284: L720-L726. 